\title{
Social deprivation and the causes of stillbirth and infant mortality
}

\author{
Z E S Guildea, D L Fone, F D Dunstan, J R Sibert, P H T Cartlidge
}

\begin{abstract}
Aims-To investigate the relation between social deprivation and causes of stillbirth and infant mortality.

Methods-Stillbirths and infant deaths in 6347 enumeration districts in Wales were linked with the Townsend score of social deprivation. In 1993-98 there were 211072 live births, 1147 stillbirths, and 1223 infant deaths. Poisson regression analysis was used to estimate the magnitude of effect for associations between the Townsend score and categories of death by age and the causes of death. The relative risk of death between most and least deprived enumeration districts was derived.

Results-Relative risk of combined stillbirth and infant death was 1.53 (95\% CI 1.35 to 1.74$)$ in the most deprived compared with the least deprived enumeration districts. The early neonatal mortality rate was not significantly associated with deprivation. Sudden infant death syndrome showed a $307 \%(95 \%$ CI $197 \%$ to $456 \%$ ) increase in mortality across the range of deprivation. Deaths caused by specific conditions and infection were also associated with deprivation, but there was no evidence of a significant association with deaths caused by placental abruption, intrapartum asphyxia, and prematurity.

Conclusions-Collaborative public health action at national and local level to target resources in deprived communities and reduce these inequalities in child health is required. Early neonatal mortality rates and deaths from intrapartum asphyxia and prematurity are not significantly associated with deprivation and may be more appropriate quality of clinical care indicators than stillbirth, perinatal, and neonatal mortality rates.

(Arch Dis Child 2001;84:307-310)
\end{abstract}

Keywords: social deprivation; cause of death; stillbirth; mortality

Social class and other measures of social deprivation are important determinants of ill health, leading to wide regional variations in mortality and morbidity. For instance, the mortality rate in children aged 1 to 4 years is 2.0 times greater for those in high mortality parliamentary constituencies compared with low mortality constituencies, and 1.8 times higher for children aged 5 to 14 years. ${ }^{1}$ Similarly, many non-lethal conditions are more common among children living in areas of high poverty than in those from affluent communities. ${ }^{2}$
Perinatal and infant mortality rates in Britain also have wide regional variations that may in part reflect an increased incidence of low birth weight and prematurity in low social class families. ${ }^{3}$ Yet mortality rates are also likely to be affected by the provision and accessibility of high quality clinical care. Indeed, it is probable that the importance of these influences varies according to the condition leading to death, and in this respect it would be advantageous to know what diseases are less dependent on deprivation.

The aim of this study was therefore to investigate the relation between social and material deprivation and the causes of stillbirth and infant mortality in a geographically defined population. We wished to determine if any causes of death, or categories of death by age (stillbirth/neonatal death/postneonatal death), are less dependent on levels of deprivation and thus more appropriate indicators of the standard of clinical care.

Subjects and methods

The data in this study relate to births to women resident in Wales in the six years 1993-98, irrespective of the place of delivery. There were 211072 registrable births, 1147 stillbirths, and 1223 infant deaths. Live births were identified with the Child Health System (CHS) database, which collects data from the birth notification form. ${ }^{4}$ Stillbirths and infant deaths were identified with the All Wales Perinatal Survey (AWPS), a population based register of mortality between 20 completed weeks of gestation and 1 year of age. ${ }^{5}$ The AWPS regional coordinating team verified complete ascertainment of mortality by cross checking with data from the CHS database and the Office for National Statistics.

Information about each death was collected on the survey questionnaire, which was normally completed by the team in whose unit the baby died. This included detailed information about the mother (medical and obstetric history, current pregnancy, labour, and delivery) collected prospectively at booking, and the baby (sex, birth weight, gestational age, clinical management, and postmortem findings). This information was used to classify the cause of death according to the clinicopathological system, modified to clarify certain ambiguities and expanded to take account of postneonatal deaths. ${ }^{67}$ For the purposes of this study, an accidental death was classified as a specific condition.

All births and deaths were assigned by postcode to the enumeration district of maternal residence using Postpoint Professional in Map Info, version 5.5. The accuracy of the postcode was checked using the Post Office PAF computer file that links address to postcode. 
Table 1 Effect of Townsend (deprivation) score on the combined stillbirth and infant mortality rate

\begin{tabular}{lllll}
\hline $\begin{array}{l}\text { Townsend score } \\
\text { (range) }\end{array}$ & $\begin{array}{l}\text { Total number of } \\
\text { stillbirths and } \\
\text { infant deaths }\end{array}$ & $\begin{array}{l}\text { Total number } \\
\text { of births }\end{array}$ & $\begin{array}{l}\text { Mortality rate } \\
\text { (per 1000 births) }\end{array}$ & $\begin{array}{l}\text { Relative risk } \\
\text { (95\% CI) }\end{array}$ \\
\hline-7.55 to -2.54 & 393 & 41758 & 9.41 & 1.00 \\
-2.54 to -0.77 & 426 & 41765 & 10.2 & $1.08(0.94,1.24)$ \\
-0.77 to 0.92 & 450 & 41744 & 10.78 & $1.15(0.98,1.32)$ \\
0.92 to 3.13 & 495 & 41767 & 11.85 & $1.26(1.1,1.44)$ \\
3.13 to 10.79 & 602 & 41779 & 14.41 & $1.53(1.35,1.74)$ \\
\hline
\end{tabular}

Table 2 Association between age at death and Townsend score

\begin{tabular}{lcccl}
\hline & $\begin{array}{l}\text { Number of } \\
\text { deaths }\end{array}$ & $\begin{array}{c}\text { Magnitude of effect } \\
(\%)(95 \% \text { CI })\end{array}$ & $\begin{array}{c}\text { Increase in mortality } \\
\text { rate over range } \%)\end{array}$ & p value \\
\hline Stillbirths & 1146 & $4.3(2.5,6.1)$ & $41(22,62)$ & 0.0001 \\
Early neonatal & 598 & $1(-1.6,3.6)$ & $8(-14,34)$ & 0.4399 \\
Late neonatal & 189 & $5.9(1.4,10.3)$ & $60(12,123)$ & 0.008 \\
Postneonatal & 433 & $10.1(7.2,13)$ & $120(77,172)$ & 0.0001 \\
Total & 2366 & $4.7(3.4,5.9)$ & $46(32,60)$ & 0.0001 \\
Perinatal & 1744 & $3.2(1.7,4.6)$ & $29(15,45)$ & 0.0001 \\
Neonatal & 787 & $2.2(0.0,4.4)$ & $20(0,42)$ & 0.0483 \\
Infant & 1220 & $5.1(3.3,6.8)$ & $50(30,71)$ & 0.0001 \\
\hline
\end{tabular}

For stillbirths and neonatal deaths the postcode used was that of the mother at the time of delivery, and for postneonatal deaths that of the infant at the time of death. Postcodes were missing or invalid in $2259(1.1 \%)$ registrable births and $4(0.17 \%)$ deaths; these cases were excluded from the analysis.

The Townsend social and material deprivation score is calculated using unemployment, car ownership, owner occupation, and overcrowding variables derived from the 1991 census. ${ }^{8}$ The individual score for each component was standardised to zero mean and unit variance across the enumeration districts in England and Wales. The Townsend score ranged from -7.55 in the least deprived enumeration district to +10.79 in the most deprived.

The relations between social deprivation and death were initially explored by ranking the enumeration districts according to Townsend score, dividing them into quintiles with approximately equal numbers of births in each, and comparing total mortality rates between the quintiles. The associations between the various categories of death by age (stillbirth, neonatal death, etc), the causes of death, and deprivation were quantified using Poisson regression analysis on data from individual enumeration districts. ${ }^{9}$ In each situation the magnitude of the effect, defined as the percentage change in the mortality rate arising from a unit change in the Townsend score, was determined. From this the percentage increase in the mortality rate between the median Townsend score in the least deprived quintile and median Townsend score in the most deprived quintile of births in Wales was estimated. All analyses were performed using SAS and SPSS 9.

\section{Results}

The combined stillbirth and infant mortality rate in individual enumeration districts ranged from $0 / 1000$ registrable births to $333.3 / 1000$ (median 0, interquartile range 0 to 17.6). No deaths were reported from 4536/6347 (71\%) enumeration districts that had births between 1993 and 1998.

The combined stillbirth and infant mortality rate increased according to the level of social deprivation (Townsend score), from 9.41/1000 in the least deprived quintile, to $14.41 / 1000$ in the most deprived quintile, a relative risk of death of 1.53 (95\% confidence interval (CI) 1.35 to 1.74 ; table 1 ).

Using Poisson regression we found that stillbirths, neonatal, and postneonatal mortality rates within enumeration districts were each significantly associated with the Townsend score of deprivation (table 2). The strongest association was for postneonatal mortality, with a magnitude of effect of $10.1 \%$ (95\% CI 7.2 to 13 ), equivalent to an increase in mortality rate across the range of deprivation of $120 \%$ (95\% CI $77 \%$ to $172 \%)$. For stillbirths the magnitude of effect was $4.3 \%$ ( $41 \%$ across the whole range) and for neonatal deaths the magnitude of effect was $2.2 \%(20 \%$ across the range). However, the association with neonatal death varied according to the age at death. In late neonatal deaths the association was significant $(\mathrm{p}=0.008)$ with a magnitude of effect of $5.9 \%$ (95\% CI $1.4 \%$ to $10.3 \%)$. In contrast, for early neonatal deaths the magnitude of effect was only $1 \%$ (95\% CI $-1.6 \%$ to $3.6 \%$ ), equivalent to an increase in mortality rate across the range of deprivation of $8 \%(95 \% \mathrm{CI}-14 \%$ to $34 \%$; $\mathrm{p}=0.4399)$.

The cause of death most strongly associated with social deprivation was sudden infant death syndrome, with a magnitude of effect of $18.7 \%$ ( $95 \%$ CI $14.2 \%$ to $23.3 \%$ ), equivalent to an increase in mortality rate across the range of $307 \%$ (95\% CI $197 \%$ to $456 \%$ ). Similarly, death caused by an unexplained stillbirth, infection, and a specific condition was also significantly associated with deprivation (table 3 ). In contrast, there was no significant association between social deprivation and death caused by placental abruption prior to the onset of labour, intrapartum asphyxia, congenital anomaly, and conditions consequent on preterm birth.

Table 3 Effect of Townsend (deprivation) score on the causes of stillbirth and infant death

\begin{tabular}{lllll}
\hline & $\begin{array}{l}\text { Number } \\
\text { of deaths }\end{array}$ & $\begin{array}{l}\text { Magnitude of effect } \\
\text { (\%) (95\% CI) }\end{array}$ & $\begin{array}{l}\text { Increase in mortality rate } \\
\text { over range (\%) (95\% CI) }\end{array}$ & $p$ value \\
\hline Sudden infant death & 165 & $18.7(14.2,23.3)$ & $307(197,456)$ & 0.0001 \\
Specific conditions and accidental deaths & 152 & $6.5(1.6,11.4)$ & $68(14,142)$ & 0.0079 \\
Infection & 143 & $6.3(1.2,11.3)$ & $65(10,140)$ & 0.0131 \\
$\begin{array}{l}\text { Unexplained death prior to onset of labour } \\
\begin{array}{l}\text { Death prior to onset of labour associated with } \\
\text { placental abruption }\end{array}\end{array}$ & 699 & $4.7(2.4,7)$ & $46(21,74)$ & 0.0001 \\
$\begin{array}{l}\text { Congenital anomaly } \\
\text { Conditions consequent on preterm birth }\end{array}$ & 176 & $4.2(-0.41,8.8)$ & $40(-3,100)$ & 0.0677 \\
Intrapartum events & 478 & $2.4(-0.76,5.6)$ & $21(-6,56)$ & 0.1301 \\
& 171 & $1.6(-1.2,4.5)$ & $14(-10,43)$ & 0.2486 \\
\hline
\end{tabular}




\section{Discussion}

This population based ecological study has shown a significant association between stillbirth and infant death and social deprivation. The relative risk of death occurring between 24 weeks gestation and 1 year of age was 1.53 times higher in the most deprived enumeration districts in Wales compared to the least deprived. Two other studies have been reported using a similar methodology. In Derbyshire, an investigation of 129 post perinatal deaths using the Jarman underprivileged area index found a relative risk of death of 1.93, and in North West Thames using the Carstairs deprivation index applied to 4243 perinatal deaths, a relative risk of 1.65 was found between the extremes of deprivation. ${ }^{10}{ }^{11}$ The lower risk in the latter study is probably related to the varying influence of deprivation on mortality rates that is dependent on the age at death of the baby. This is consistent with the findings in our study, in which postneonatal deaths were increased by $120 \%$ in the most deprived enumeration districts compared to the least deprived, stillbirths were increased by $41 \%$, and neonatal deaths by $20 \%$. We also found a significant association between social deprivation and deaths caused by unexplained stillbirth, infection, a specific condition, and in particular the sudden infant death syndrome. In contrast, death caused by intrapartum asphyxia, congenital anomalies, prematurity, and also early neonatal deaths were not significantly associated with deprivation. Nevertheless, since there are a large number of early neonatal deaths and deaths caused by prematurity, even a small effect, which cannot be excluded by our analysis, could result in a large number of deaths.

PUBLIC HEALTH

The high rate of stillbirth and infant mortality in deprived areas is a cause of great concern and will be distressing to many people within those communities. Reducing inequalities in mortality requires collaborative action within communities, and improvements in wider economic and educational environments. This is particularly relevant given that the trends in the social determinants of stillbirth and infant death in Britain are not encouraging. The proportion of 15 year old girls who are regular cigarette smokers increased from $25 \%$ in 1982 to $29 \%$ in 1998 , the conception rate in under 16 year olds remains high, and the percentage of low birthweight babies is rising..$^{513}$

The evidence for effective interventions to reduce health inequalities is highlighted in the Acheson report, Independent inquiry into inequalities in health. ${ }^{14}$ The report recommends action to reduce poverty in families, improve the nutrition of women and children, promote sexual health, reduce the prevalence of smoking in pregnancy, reduce alcohol related harm, and promote breast feeding, and advocates the social and emotional support of parents. In addition there need to be improvements in education, housing, employment, and the physical environment. These are political objectives that are best achieved by working across traditional government departmental boundaries to promote better public health.
OBSTETRIC AND NEONATAL CARE

Deaths caused by intrapartum asphyxia and prematurity were not significantly associated with social deprivation. This implies that public health interventions aimed at reducing social inequalities are less likely to reduce the mortality rate owing to these conditions. It is more likely that improvements in the quality of obstetric and neonatal care will lead to a reduction in these deaths. Intrapartum asphyxia in particular has been closely linked to the quality of perinatal care, and the availability of experienced staff around the time of birth. ${ }^{15}$ Similarly, the chances of survival of preterm infants are probably best improved by high quality neonatal intensive care.

Caution is required when interpreting the lack of significant association between congenital anomalies and deprivation. Only babies with severe anomalies were included in our study, and moreover it is a heterogeneous group in which the underlying causes of the anomalies were probably numerous. A study conducted in England and Wales investigating variations in mortality owing to congenital malformations according to mother's country of birth discovered that mortality was inversely related to social class in most ethnic groups. ${ }^{16}$

Perinatal, stillbirth, and neonatal mortality rates are often used as summary statistics to evaluate the quality of clinical care ${ }^{17}$ However, we have shown that these rates are significantly associated with social deprivation, highlighting the importance of interpreting these figures with caution. In contrast, the early neonatal mortality rate is the least affected by deprivation, and this may be a better measure of the quality of care than other routinely available rates.

In conclusion, we have found that postneonatal infant mortality in particular is strongly associated with social deprivation. Collaborative public health action at national and local levels to target resources in deprived communities and reduce inequalities in child health is required. We also suggest that as deaths from intrapartum asphyxia and prematurity and the early neonatal mortality rate are not significantly associated with deprivation, mortality rates from these causes may be the most appropriate indicators of the quality of clinical care.

The All Wales Perinatal Survey incorporates CESDI and is funded by the National Assembly for Wales.

\section{Appendix}

DEFINITIONS OF MORTALITY RATES

- Stillbirths-late fetal deaths after 24 weeks gestation

- Early neonatal-deaths occurring in the first six days of life

- Perinatal-stillbirths, and deaths in the first six days of life

- Late neonatal-deaths at 7-27 completed days of life

- Neonatal-deaths in the first 27 completed days of life

- Postneonatal-deaths at age 28 days and over but under 1 year

- Infant-deaths at age under 1 year (excluding stillbirths). 
1 Shaw M, Dorling D, Gordon D, Davey Smith G. The widening gap; health inequalities and policy in Britain. Bristol: The ing gap; health inequali

2 Reading R. Poverty and the health of children and adolescents. Arch Dis Child 1997;76:463-7.

3 MacFarlane A, Mugford M. Characteristics of parents and the circumstances in which they live. In: MacFarlane A Mugford M, eds. Birth counts: statistics of pregnancy and childbirth. London: HMSO, 1984.

4 Andrews J, Cotter M, Richards R, Lewis D. Report on mater nal data/information aspects of the child health system. Cardiff: Welsh Office, 1996.

5 Cartlidge PHT, Stewart JH, Hopkins JM, et al. All Wales Perinatal Survey and Confidential Enquiry into Stillbirths and Deaths in Infancy. Annual report 1998. Cardiff: Perinatal Survey Office, 1999

6 Wigglesworth JS. Monitoring perinatal mortality - a pathophysiological approach. Lancet 1980;ii: 684-6.

7 Keeling JW, MacGillivray I, Golding J, et al. Classification of perinatal death. Arch Dis Child 1989;64:1345-51.

8 Townsend P, Phillimore P, Beattie A. Health and deprivation: inequality in the North. London: Routledge, 1988.

inequality in the North. London: Routledge, 1988.
Dobson AJ. An introduction to generalised linear models. Dobson AJ. An introduction to gener
London: Chapman and Hall, 1990.
10 Newlands M, Adamson E, Ghulam S, et al. Jarman index related to post-perinatal mortality. Public Health 1992;106: $163-5$.

11 Martuzzi M, Grundy C, Elliott P. Perinatal mortality in an English health region: geographical distribution and association with socio-economic factors. Paediatr Perinat Epidemiol 1998;12:263-76.

12 Office for National Statistics. Smoking, drinking and drug use among young teenagers in 1998. London: HMSO, 1999.

13 Office for National Statistics. Birth Statistics Series FM1 nos 17-27. London: HMSO, 1988-99.

14 Acheson, Sir D. Independent inquiry into inequalities in health (Acheson report). London: The Stationery Office, 1998.

15 Stewart JH, Andrews J, Cartlidge PHT. Numbers of deaths related to intrapartum asphyxia and timing of birth in all Wales perinatal survey, 1993-5. BMF 1998;316:657-60.

16 Balarajan R, Soni RV, Botting B. Mortality from congenital malformations in England and Wales: variations by mother's country of birth. Arch Dis Child 1989;64:145762 .

17 Cartlidge PHT, Stewart JH. Effect of changing the stillbirth definition on evaluation of perinatal mortality rates. Lancet 1995;346:486-8.

\section{Rapid responses}

Letters on the following papers have been published recently as rapid responses on the $A D C$ website. To read these letters visit www.archdischild.com and click on "Read rapid responses":

Successful implementation of spacer treatment guideline for acute asthma. CVE Powell, GR Maskell, et al. Arch Dis Child 2001;84:142-6.

Randomised controlled trial of infantile colic treated with chiropractic spinal manipulation. E Olafsdottir, S Forshei, G Fluge, et al. Arch Dis Child 2001;84:138-41.

Alcohol misuse. WJ Robson. Arch Dis Child 2001;84:95-7.

Medical ethics and Islam: principles and practice. AR Gatrad, A Sheikh. Arch Dis Child 2001;84:72-5.

Randomised controlled trial of the effect of ventilation tubes (grommets) on quality of life at age 1-2 years. MM Rovers, PFM Krabbe, H Straatman, et al. Arch Dis Child 2001;84:45-9.

Economic evaluation of strategies for managing crying and sleeping problems. S Morris, I St James-Roberts, J Sleep, et al. Arch Dis Child 2001;84:15-19.

The need for and the role of a coordinator in child health surveillance/promotion. $M$ Blair. Arch Dis Child 2001;84:1-5.

Do presenters to paediatric meetings get their work published? FAI Riordan. Arch Dis Child 2000;83:524-6.

Medication errors in a paediatric teaching hospital in the UK: five years operational experience. LM Ross, J Wallace, JY Paton, et al. Arch Dis Child 2000;83:492-7.

In defence of the Children Act. B Hale; N Speight, J Wynne. Arch Dis Child 2000;83:463-7.

An association between sudden infant death syndrome (SIDS) and Helicobacter pylori infection. JR Kerr, A Al-Khattaf, AJ Barson, et al. Arch Dis Child 2000;83:429-34.

The treatment of convulsive status epilepticus in children. The Status Epilepticus Working Party, et al. Arch Dis Child 2000;83:415-19.

Neonatal screening for hearing impairment. CR Kennedy, D Hall, A Davis. Arch Dis Child 2000;83:377-83.

Xylitol and acute otitis media. Archivist. Arch Dis Child 1999;80:376.

If you would like to post an electronic response to these or any other articles published in the journal, please go to the website, access the article in which you are interested, and click on "eLetters: Submit a reponse to this article" in the box in the top right hand corner. 